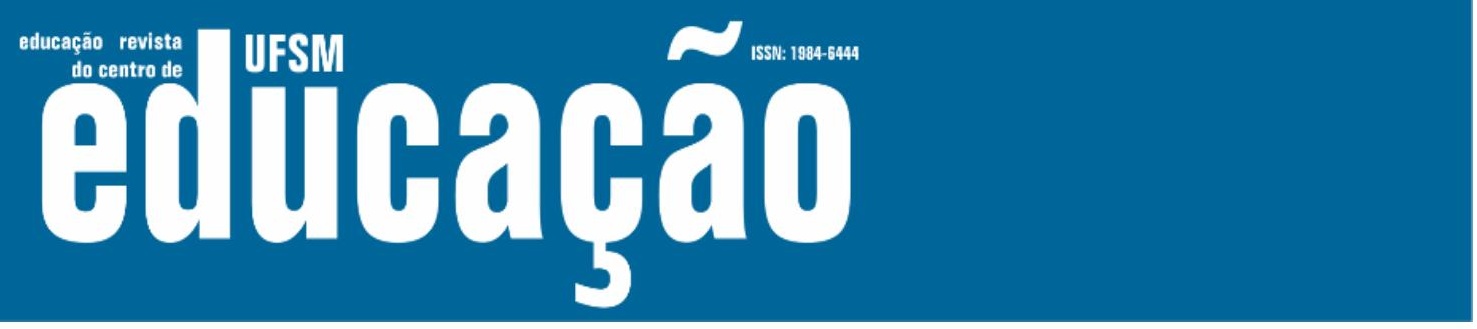

ISSN: 1984-6444 | http://dx.doi.org/10.5902/1984644439103

\title{
Modelos de formação de professores de História: um estudo comparado entre a Universidade Federal da Fronteira Sul (Brasil) e a Universidade do Minho (Portugal) ${ }^{1}$
}

History teachers training models: a comparative study between the Federal University of the Southern Border (Brazil) and the University of Minho (Portugal)

Halferd Carlos Ribeiro Junior

Professor Adjunto na Universidade Federal da Fronteira Sul, Erechin, Rio Grande do Sul, Brasil. halferd.junior@uffs.edu.br - https://orcid.org/0000-0002-0262-0727

Maria Glória Parra Santos Solé

Professora Auxiliar na Universidade do Minho, Braga, Portugal. gsole@ie.uminho.pt - https://orcid.org/0000-0003-3383-5605

Recebido em 17 de julho de 2019

Aprovado em 22 de junho de 2020

Publicado em 25 de setembro de 2020

\section{RESUMO}

A sociedade contemporânea, marcada pela tecnologia de informação e comunicação, exige do indivíduo uma postura proativa, flexível, e em constante aprendizado, para a superação de seus limites frente as constantes transformações tecnológicas, econômicas, políticas, sociais e culturais. Nesse cenário, apresentamos os resultados de uma pesquisa que aborda o estágio supervisionado na formação inicial do professor de história, da experiência desenvolvida na Universidade Federal da Fronteira Sul - Campus Erechim, Brasil, e da Universidade do Minho, Braga, Portugal, indagando acerca do paradigma que sustenta a metodologia proposta para o ensino de história e o perfil do professor de história desejado.

Palavras-Chaves: Formação de Professores; Estágio Supervisionado, Educação Histórica. 


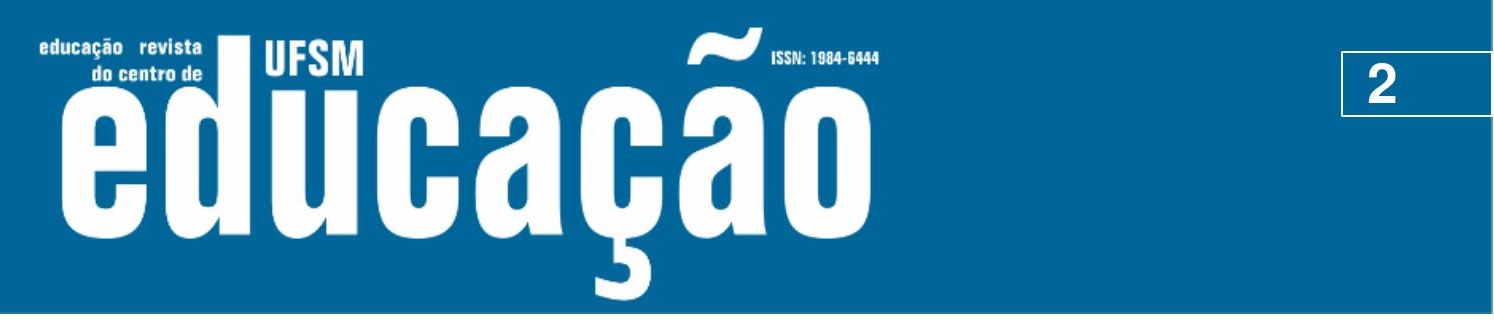

ISSN: 1984-6444 | http://dx.doi.org/10.5902/1984644439103

\section{ABSTRACT}

Contemporary society, noticeable by the information and communication technology, demands from the individual a proactive, flexible, and constantly learning attitude to overcome its limits in the face of constant technological, economic, political, social and cultural transformations. In this scenario, we present the results of a research that examines the supervised internship in the history teacher's initial training, the experience developed at the Federal Frontier University - Campus Erechim, Brazil, and the University of Minho, Braga, Portugal, paradigm that supports the methodology proposed for the teaching of history and the profile of the desired history teacher.

Keywords: Teacher training; Supervised Internship, Historical Education.

\section{Introdução}

Inicialmente, a construção desse artigo esteve vinculada aos debates desencadeados pela reforma educacional em curso no Brasil, a Reforma do Ensino Médio (2016), a Base Nacional Comum Curricular (Brasil, 2016; 2017), o projeto de uma escola sem partido, e a política de formação de professores (2015), temáticas que ganharam uma importância política mais relevante após a queda do governo Dilma. Ao dirigirmos a nossa atenção para Portugal, percebemos a existência e permanência de um cenário de reforma educacional (GROSSO, 2017; 2015), a política de formação de professores pelos desdobramentos do Tratado de Bolonha ${ }^{2}$ (LEITE: FFERNANDES, 2013), Currículo Nacional do Ensino Básico - Competências Essenciais (PORTUGAL, 2001), Reforma do Ensino Secundário (2004), Metas de Aprendizagem (PORTUGAL, 2010), Revogação do Currículo Nacional do Ensino Básico (PORTUGAL, 2011), Metas Curriculares (PORTUGAL, 2013).

No passado recente, imbricado na crise econômica desencadeada pela queda do banco Lehman Brothers (15/09/2008), assistimos a presidência de Barack Obama (2009 - 2016) e também do Lula (2003-2010) e de Dilma Rousseuf (2011 $31 / 08 / 2016)$, em que a temática dos direitos sociais esteve em pauta; por exemplo o Obamacare nos EUA e a ampliação do acesso ao ensino superior no Brasil. A vitória de Trump à presidência dos EUA, e em âmbito local, a tomada do poder pelo Michel Temer, Brasil, são indicativos de uma reviravolta do projeto de governo que estava em curso. 


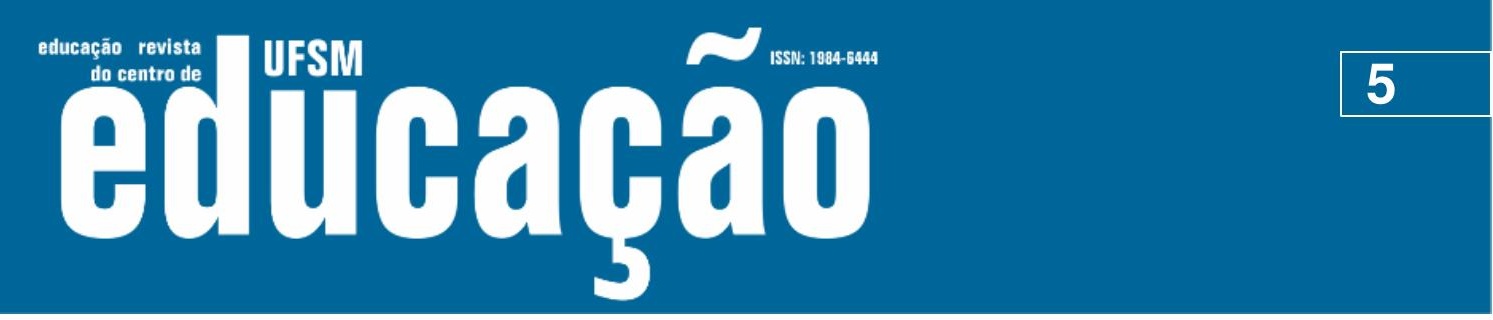

ISSN: 1984-6444 | http://dx.doi.org/10.5902/1984644439103

\section{Formação Inicial do Professor de História}

\section{Universidade Federal da Fronteira Sul - Campus Erechim}

Para Zamboni e Mesquita (2008), nos anos 1970, a principal preocupação das graduações em História era a transmissão dos saberes da ciência de referência em detrimento da formação pedagógica do professor; restringindo-se ao estágio e as disciplinas pedagógicas, estudadas na Faculdade de Educação, configurando a situação de 3 (ou 4) anos de estudos de conhecimento específico, e mais 1 ano para as disciplinas pedagógicas, uma formação bi-etápica. Contribuindo, assim, para uma ação docente que estava preocupada apenas com a transmissão de conhecimentos, na memorização de fatos, datas e heróis.

Nos anos 80, no processo histórico de derrubada da Ditadura Civil Militar, professores e pesquisadores articularam o construtivismo com diferentes correntes historiográficas, defendendo uma prática de ensino planejada a partir da história de vida dos alunos, o uso de temas significativos, partindo do presente para depois relacionar com outros momentos históricos e espaços geográficos distintos. Dessa forma, os temas e as formas de se ensinar História se multiplicaram, valorizando a utilização de documentos históricos, entrevistas, imagens; os alunos deixaram de ser um agente passivo no processo de ensino e/ou aprendizagem, ao mesmo tempo em que foram considerados sujeitos históricos. Novos objetos e novas abordagens foram discutidos para o currículo escolar, como a história dos excluídos e da classe operária. O ensino de história foi transformado para atender a necessidade de construção da sociedade democrática, e, consequentemente, implicando no questionamento da formação inicial do professor de História.

Fonseca e Couto (2008) argumentam que após a Lei de Diretrizes e Bases da Educação n. 9394/96, em 4 de dezembro 1997, o Ministério da Educação (MEC) lançou o edital n. 4 convocando as instituições de ensino superior para a construção de propostas de reformulação das graduações. Entre junho e novembro de 1998 a Comissão de Especialistas de História do MEC, com representantes da ANPUH (Associação Nacional de História), reuniu-se para a elaboração das diretrizes para as 


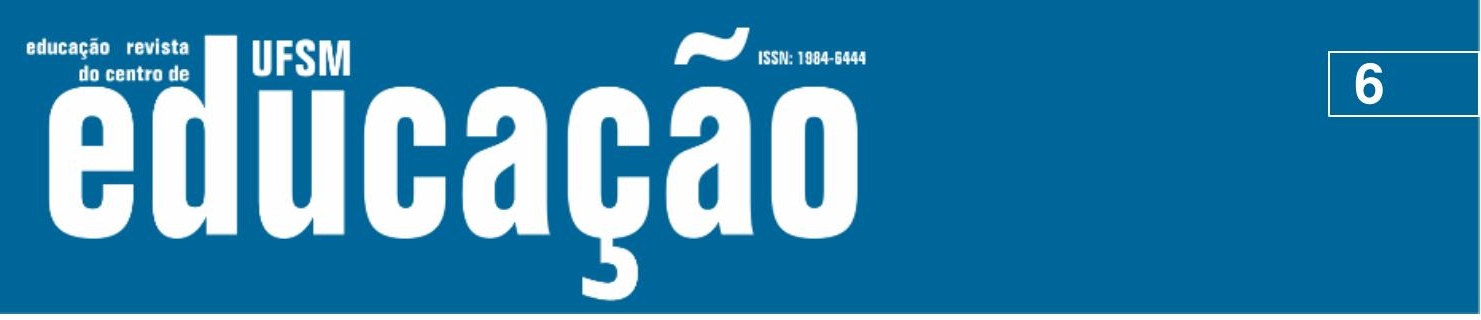

ISSN: 1984-6444 | http://dx.doi.org/10.5902/1984644439103

graduações em História. Em 3 de abril de 2001, a Câmara de Educação Superior aprovou por unanimidade as Diretrizes Curriculares Nacionais dos Cursos de História. Segundo as autoras, esse documento tem como objetivo a formação do historiador em detrimento do professor de história.

Em maio de 2000, o MEC encaminhou para o Conselho Nacional de Educação (CNE) uma proposta para a construção das diretrizes para a formação do professor; o CNE nomeou uma comissão com representantes das câmaras da educação básica e do ensino superior, para analisar tal proposta. De acordo com Fonseca e Couto,

A proposta de diretrizes também foi submetida à apreciação da comunidade educacional em cinco audiências públicas regionais, uma reunião institucional, uma reunião técnica e uma audiência pública nacional. Em 8/5/2001, a Câmara de Educação Superior aprovou as Diretrizes Curriculares Nacionais para a Formação de Professores da Educação Básica, em nível superior, curso de licenciatura, de graduação plena (FONSECA; COUTO, 2008, p.111).

Dessa forma, institucionalizava que a formação do professor deveria ocorrer por meio de licenciatura plena, em conformidade com a LDB de 1996, alterando definitivamente a concepção de licenciatura curta para a formação de professores que foi construída durante a Ditadura Civil Militar. As Diretrizes Curriculares Nacionais para a Formação de Professores da Educação Básica pressupõem a construção do professor-pesquisador, capaz de compreender a realidade que o cerca, tendo domínio dos conhecimentos da ciência de referência, apropriando-se do uso das tecnologias de informação e comunicação, tendo habilidades para desenvolver estratégias metodológicas eficazes de ensino, articulando, assim, saberes práticos, específicos, pedagógicos, psicológicos. Tal dinâmica, indica uma permanência da tensão na formação do professor de história, por um lado, a comunidade de especialista de história, tendo como foco a formação do historiador, enquanto o MEC e as demandas sociais requerendo que seja privilegiado a formação do professor de história.

É o papel das instituições de ensino superior elaborar o Projeto Político Pedagógico de suas graduações, obedecendo orientações legais e as avaliações periódicas do MEC. A Licenciatura em História da UFFS, campus Erechim, é organizada por meio da sua Matriz Curricular aprovada em 2012. O perfil do profissional almejado é formar professores para atuar no Ensino Fundamental e 


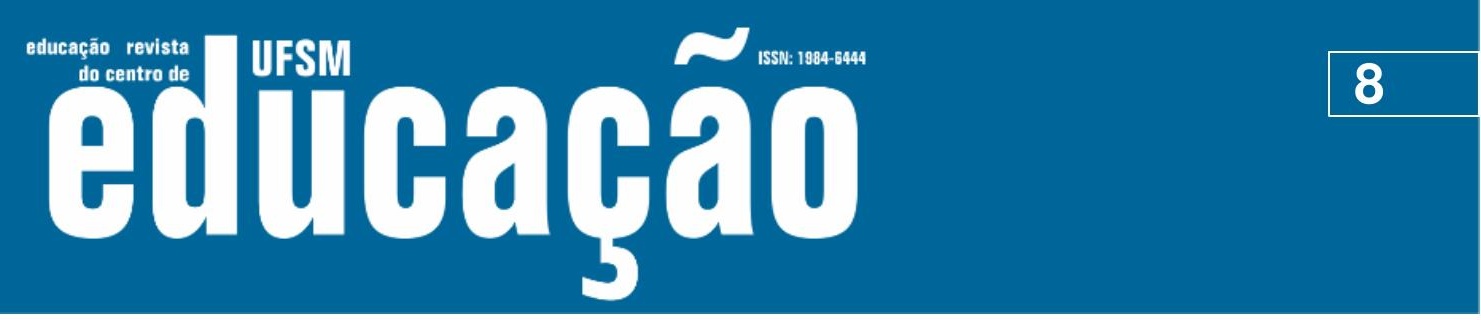

ISSN: 1984-6444 | http://dx.doi.org/10.5902/1984644439103

O estágio de observação deve dar subsídios para compreensão da realidade em que os alunos estão inseridos para a fundamentação da prática pedagógica do estágio de regência. Para tanto, as reflexões de Conceição (2010), Lima (2013) e André (2005) são mobilizadas para a compreensão da realidade escolar e da relação da juventude com a cultura contemporânea.

Conceição (2010) investigou a consciência histórica latino-americana dos alunos do Colégio de Aplicação da UFSC em que cursavam a disciplina Estudos Latino-Americanos na $7^{\text {ạ }}$ série em 2009. Para execução dessa pesquisa, aplicou um questionário socioeconômico-cultural, survey, a fim de mapear o perfil e as áreas de interesses dos alunos, observou as aulas durante o período letivo 2009, e aplicou atividades para os alunos elaborarem narrativas sobre os países e a cultura latinoamericana, que serviu de base documental para a análise de sua interpretação. $O$ trabalho da Conceição serviu como lastro para a observação, coleta de dados, análises e interpretações da realidade escolar a fim de possibilitar a construção do projeto de intervenção pedagógica, bem como a organização e metodologia das aulas que seriam ministradas durante o estágio.

A tese de Lima (2013) teve como objetivo estudar a relação dos alunos e professores com os artefatos da cultura contemporânea e a intertextualidade da aula de história. Para a realização dessa pesquisa, aplicou questionário socioeconômico, observou as aulas de história, e entrevistou professores, em duas escolas da Rede Municipal de Itatiba, região metropolitana de Campinas, no estado de São Paulo. Os resultados produzidos demostraram que a televisão, o cinema (filmes), a internet, principalmente as redes sociais e para a comunicação, são os principais artefatos utilizados pelos alunos e professores, no entanto, dificilmente foi perceptível um impacto significativo nas aulas de história observadas pela pesquisadora; tal circunstância instigaram os estagiários a olhar para essa dinâmica para o planejamento das atividades que seriam desenvolvidas com os alunos.

A aplicação do survey, a produção de dados quantitativos sobre o perfil dos alunos, é cotejado com a observação da comunidade, da escola e dos alunos em ambientes formais e não formais de ensino, a relação dos alunos com os artefatos da cultura contemporânea, com base nas reflexões da etnografia da prática escolar 


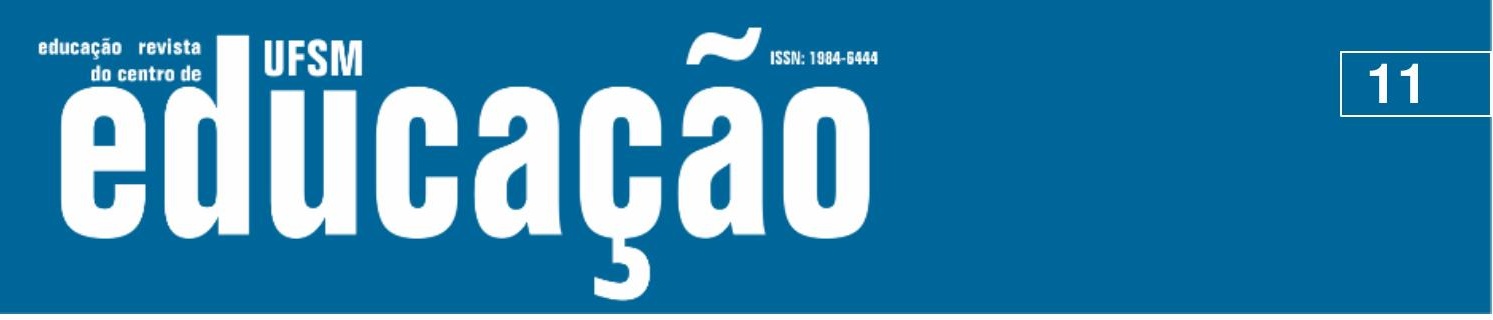

ISSN: 1984-6444 | http://dx.doi.org/10.5902/1984644439103

mestrado em ensino, tendo como pressuposto "educar investigando e investigar educando". Em síntese:

No caso da Universidade do Minho, os dois desafios foram equacionados aquando do desenho do modelo de estágio, procurando-se criar condições para que a investigação pudesse ocupar um lugar de relevo na prática e na elaboração do relatório, no quadro de uma formação reflexiva. Foi possível consensualizar um modelo comum a todos os mestrados em ensino, onde se explicitam pressupostos e princípios de orientação reflexiva, e onde se prevê uma articulação estreita entre a prática pedagógica e o relatório final, ambos focados num "projeto de intervenção pedagógica supervisionada" que articula investigação e ensino. O modelo pretende conferir à prática pedagógica uma natureza transformadora e emancipatória e podemos dizer que se aproxima da criação de um "terceiro espaço" (Zeichner, 2010), de natureza multidisciplinar e teórico-prática, onde os futuros educadores e professores devem educar investigando e investigar educando, e onde a ação educativa envolve a confluência de saberes disciplinares e educacionais, experienciais e teóricos, substantivos e processuais. Nesta perspectiva, o estagiário é entendido como um consumidor crítico e produtor criativo do conhecimento e a supervisão pedagógica deverá assentar nos princípios da indagação crítica, intervenção crítica, democraticidade, participação e emancipação, apoiando o desenvolvimento de planos de intervenção concebidos por referência a uma visão democrática da educação escolar [...] (VIEIRA et al., 2013, p. 2644).

O Estágio Profissional tem o objetivo de articular os conhecimentos debatidos nas disciplinas que compõem o mestrado em ensino com a realidade escolar, "promover a intervenção crítica nos contextos pedagógicos no quadro de uma visão transformadora da pedagogia escolar, e incentivar uma cultura investigativa e colaborativa na formação profissional” (MELO, 2015, p. 46). Para tanto, é crucial a construção, planejamento, execução e análise do Projeto de Intervenção Pedagógica Supervisionada (PIPS), uma metodologia da prática de ensino pautada no conceito de investigação/ação.

A unidade curricular Estágio Profissional é desenvolvida em três módulos: 1) Análise do Contexto de Intervenção Pedagógica, sendo subdivido em Observação de Práticas da Educação e Projeto Curricular e Ambientes de Aprendizagem/Gestão de Problemas de Comportamento e Aprendizagem; 2) Seminário de História; 3) Intervenção Pedagógica. No primeiro módulo, o objetivo é que o professor estagiário observe e conheça a realidade escolar em que desenvolverá a regência; os alunos assistem as aulas dos professores, familiarizando-se com a turma, a fim de indagar quais são as práticas de ensino dominantes; no segundo item desse módulo, as discussões abordam a proposta curricular oficial para o ensino de história, as 


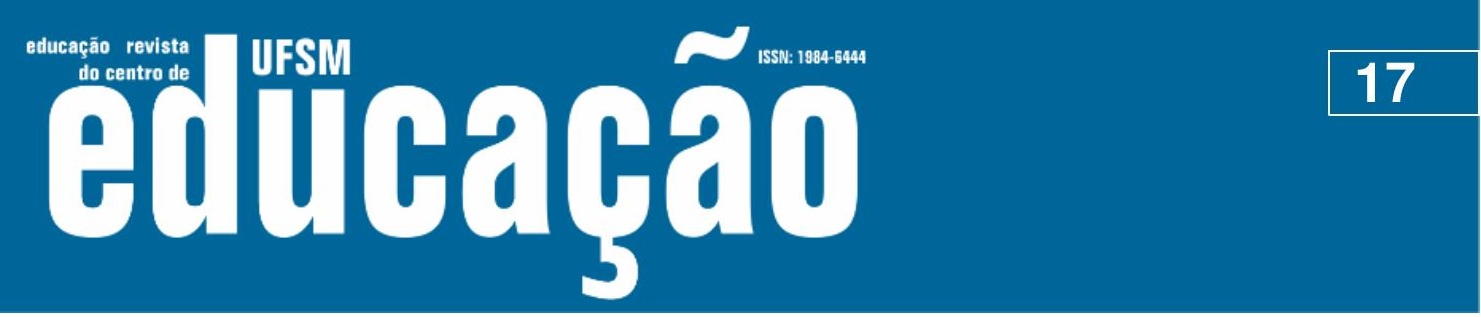

ISSN: 1984-6444 | http://dx.doi.org/10.5902/1984644439103

Enquanto no Brasil, a aula analisada foi ministrada para alunos do 6.ำ 8. aanos, centrou-se na análise de fontes, através da exposição dos objetos familiares utilizados pelos pais ou avós dos alunos, visando a construção de uma exposição museística. Nesse caso, o conceito que fundamenta a prática de ensino é a produção do conhecimento histórico escolar (Bittencourt, 2004) em que o professor mobiliza as estratégias de produção do conhecimento do historiador para servir como lastro da aula, a ideia da crítica aos documentos, análise de sua produção, circulação, sentidos e significados, são considerados elementos importantes para que os alunos aprendam a crítica histórica e a utilizem para entender o mundo que o cerca.

As reformas educacionais em curso, influenciadas pelas avaliações externas, tem demonstrado poucos efeitos imediatos na essência da formação inicial de professores. Os casos que abordamos, denota a permanência da trajetória profissional e acadêmica para a construção de uma metodologia de ensino para o ensino de história, que busca a formação de um cidadão crítico, autônomo, capaz de compreender o mundo que o cerca, e posicionar-se nele, para o fortalecimento da democracia, dos diretos humanos, e da justiça social.

\section{Referências}

ANDRÉ, Marli Eliza Dalmazo Afonso de. Etnografia da Prática Escolar. Campinas: Papirus, 2005.

BITTENCOURT, Circe Maria Fernandes. Ensino de História: Fundamentos e Métodos. São Paulo: Cortez 2004.

BRASIL. Ministério da Educação. Base Nacional Comum Curricular: Segunda Versão Revista. Brasília: MEC, 2016.

BRASIL. Ministério da Educação. Base Nacional Comum Curricular: Educação é a Base. Brasília: MEC, 2017.

CONCEIÇÃO, Juliana Pirola da. Ensino de História e consciência histórica no Colégio de Aplicação da UFSC (Dissertação de Mestrado). Florianópolis: Universidade Federal de Santa Catarina, 2010.

FELÍCIO, Helena Maria dos Santos; SILVA, Carlos. Conhecimento Escolar e Formação de Professores. Revista Eletrônica Pesquiseduca. 9(18), 251-261, 2017. 


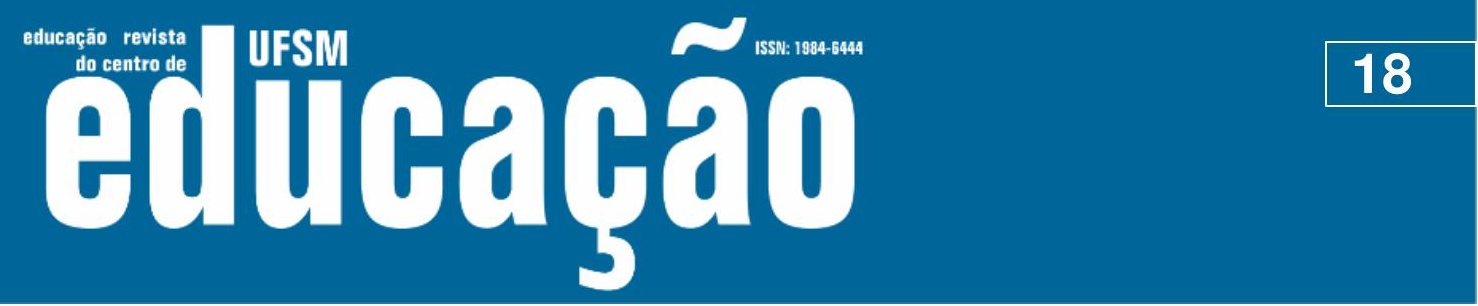

ISSN: 1984-6444 | http://dx.doi.org/10.5902/1984644439103

FONSECA, Selva Guimarães; COUTO, Regina Célia do. A Formação de Professores de História no Brasil: Perspectivas Desafiadoras do Nosso Tempo. In.: ZAMBONI, Ernesta; FONSECA, Selva Guimarães (Org.). Espaços de Formação do Professor de História. Campinas: Papirus, 2008.

FONSECA, Madalena; FRIÃES, Rita. A Formação de Professores do Ensino PréEscolar, Básico e Secundário no Ensino Superior em Portugal: do Processo de Bolonha à Atualidade. Tempo dos Professores: Programa e Resumos. Porto: Universidade do Porto, 2017.

GROSSO Luís Correia. A História no Ensino Básico em Portugal no Último Quartel: Perspectiva Curricular. Diálogos: Revista do Departamento de História e do Programa de Pós-Graduação em História. 15(1), 289-305, 2015.

GROSSO Luís Correia. Aprender História em Democracia. Conselho Nacional em Educação. Lei de Bases do Sistema Educativo: Balanço e Prospetiva. (pp. 157220), Lisboa: CNE, 2017.

LIMA, Elaine Aparecida Barreto Gomes de. A Escola como não Lugar no Ensino de História: Redes, Conexões e Cultura Contemporânea (Tese de Doutorado). Campinas: Universidade Estadual de Campinas, 2013.

LEITE, Carlinda; FERNANDES, Preciosa. A Formação Inicial de Professores em Portugal: para uma Reflexão sobre o Modelo Decorrente do Processo de Bolonha. In.: LOPES, Amélia (Org.). Formação Inicial de Professores e de Enfermeiros: Identidades e Ambientes. Porto: Livpsic, 2013.

MELO, Maria do Céu de. A Formação de Professores de História em Portugal: Práticas Pedagógicas e Investigativas. Revista História Hoje, 4(7), 41-61, 2015.

PORTUGAL. Ministério da Educação e Ciência. Lei n. 46/1986, de 14 de outubro:

Lei de Bases do Sistema Educativo. Lisboa: Diário da República, 1986.

PORTUGAL. Ministério da Educação e Ciência. Currículo Nacional do Ensino Básico - Competências Essenciais. Lisboa: MEC, 2001.

PORTUGAL. Ministério da Educação e Ciência. Despacho n. 9 17169/2011, de 23 de Dezembro (revoga o documento Currículo Nacional do Ensino Básico Competências Essenciais (ME-DEB, 2001). Lisboa: Diário da República: 2011.

PORTUGAL. Ministério da Educação e Ciência. Metas de Aprendizagem. Lisboa: MEC, 2010.

PORTUGAL. Ministério da Educação e Ciência. Metas Curriculares de História: 7ำ

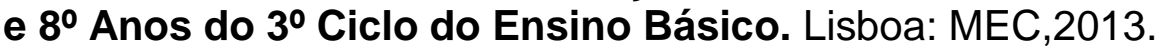




\section{Wen

ISSN: 1984-6444 | http://dx.doi.org/10.5902/1984644439103

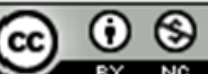

This work is licensed under a Creative Commons Attribution-NonCommercial 4.0 International (CC BY-NC 4.0)

\section{Nota}

\footnotetext{
${ }^{1}$ This work is funded by CIEd- Research Centre on Education, Intituto de Educação, UMinho, through national funds, of FCT/MCTES-PT. Este artigo está em conformidade com os procedimentos éticos estabelecidos para a pesquisa científica e com os procedimentos éticos de produção de dados com seres humanos.

2 Declaração conjunta de Ministros da Educação de países europeus que se reuniram na cidade de Bolonha, Itália, em 19 de junho de 1999, em que estabeleceu princípios e compromissos para o Ensino Superior. Assinaram a Declaração: Alemanha, Áustria, Bélgica, Bulgária, Dinamarca, Eslováquia, Eslovênia, Espanha, Estônia, Finlândia, França, Grécia, Hungria, Islândia, Irlanda, Itália, Letônia, Lituânia, Luxemburgo, Malta, Noruega, Países Baixos, Polônia, Portugal, Romênia, Suécia, Suíça, Reino Unido e República Tcheca.
} 